\title{
Representações de estudantes universitários sobre alunos cotistas: confronto de valores*
}

\author{
Maria Suzana De Stefano Menin \\ Alessandra de Morais Shimizu \\ Divino José da Silva \\ Universidade Estadual Paulista \\ Fabio Lorenzi Cioldi \\ Fabricio Buschini \\ Universidade de Genebra
}

\section{Correspondência}

Maria Suzana De Stefano Menin Centro Educacional UNESP

Rua Roberto Simonsen, 305 19060-900 - Presidente Prudente - SP e-mail: sumenin@uol.com.br
*Bolsa CAPES. Agradecemos à FUNDUNESP, pela apresentação desta no CONPSI 2007.

\section{Resumo}

A inclusão da política de cotas, nas universidades brasileiras, é recente. Apesar da adesão de várias instituições de ensino, esse tipo de política tem gerado posições contraditórias. Este estudo teve como objetivo investigar quais valores estão mais presentes na avaliação que universitários fazem a respeito de supostos usuários das cotas. Na pesquisa, foram aplicados diferentes tipos de questionários em 403 estudantes de uma universidade pública paulista, os quais objetivaram verificar se suas representações sobre esse tema variavam conforme as possibilidades de ingresso na universidade, a saber: vestibular simples, cursinhos para alunos carentes e cotas e, conforme os públicos-alvo enfocados, negros ou alunos de escolas públicas. Como método de análise, foi utilizado o programa ALCESTE e, como recurso complementar, a análise de conteúdo. Os resultados demonstraram que há uma rejeição às políticas relacionadas às cotas, uma vez que estas foram percebidas como mais ameaçadoras do que aquelas referentes ao vestibular e ao cursinho gratuito. Na grande parte das respostas dadas pelos alunos, fica evidente o conflito de valores: mérito versus igualdade compensatória. 0 vestibular, baseado apenas no mérito, é representado como o sistema mais justo para ingresso de alunos de escola pública e, principalmente de negros, na universidade. Valores como justiça, igualdade, esforço próprio, sobre os quais a maioria dos universitários respalda suas respostas contrárias às cotas, estão sendo questionados pelas políticas de ação afirmativa, o que indica que enfrentá-los é o grande desafio posto a essas políticas.

\section{Palavras-chave}

Políticas afirmativas - Cotas na universidade - Valores - lgualdade compensatória. 


\title{
University students' representations of quota students: a confrontation of values*
}

\author{
Maria Suzana De Stefano Menin \\ Alessandra de Morais Shimizu \\ Divino José da Silva \\ Universidade Estadual Paulista \\ Fabio Lorenzi Cioldi \\ Fabricio Buschini \\ Universidade de Genebra
}

Contact

Maria Suzana De Stefano Menin

Centro Educacional UNESP

Rua Roberto Simonsen, 305

19060-900-Presidente Prudente-SP

e-mail: sumenin@uol.com.br

Supported by a CAPES scholarship.

\begin{abstract}
The introduction of a policy of quotas in Brazilian universities is recent and, despite being supported by various institutes of education, this kind of policy has faced opposition. The present study has as its objective to investigate what are the values more frequently present in the evaluations university students make of quotas users. Different types of questionnaires were applied to 403 students of a public university of the State of São Paulo, with the purpose of identifying if their representations about this issue varied according to the entry channel to the university, namely, simple exam, preparatory courses for disadvantaged students, and quotas, and according to the target public in question: black students or students from public schools. As a method of analysis, the study made use of the ALCESTE program and, as a complementary resource, content analysis. The results show the rejection to quota policies, since they are perceived as more threatening than policies related to entrance exams and free prep courses. In most of the answers given by the students, a conflict of values becomes clear: merit versus compensatory equality. The entrance exam, solely based on merit, is represented as the fairest system for pupils from public schools, and particularly for black students, to enter the university. Values such as justice, equality and self-effort, upon which most university students base their answers against quotas, are being questioned by affirmative action policies, indicating that reckoning with them is the biggest challenge these policies have to face.
\end{abstract}

\section{Keywords}

Affirmative policies - University quotas - Values - Compensatory equality. 
A adoção de cotas, em nossas universidades, é recente. A implementação dessa proposta teve início em 2001, na Universidade Estadual do Rio de Janeiro (UERJ) e na Universidade Nacional de Brasília (UnB). Hoje, esse projeto de $\operatorname{cotas}^{1}$ se expandiu para mais de 20 universidades, de diversas regiões do Brasil. Apesar da adesão de várias instituições de ensino, esse tipo de política tem gerado posições contraditórias. Há pesquisas que mostram ceticismo e revelam posições contrárias por parte da opinião pública, com base em argumentos como: seria um privilégio restrito aos negros, excluindo outras minorias; seria mais justo privilegiar alunos de escolas públicas, já que o problema da pouca representação de alunos negros nas universidades estaria ligado à pobreza e à má qualidade do ensino público; as cotas estimulariam o preconceito racial por meio da estigmatização dos alunos beneficiados; produziriam uma perda de qualidade do ensino e ainda haveria dificuldade de selecionar os indivíduos que deveriam se beneficiar das cotas, uma vez que haveria a crença de que não há uma identidade de cor definida no país. (Santos, 2003; Camargo, 2005a; Augusto Brandão, 2004; Veloso, 2005). Esses argumentos contrários às cotas apóiam-se no valor da igualdade da capacidade e de direitos entre negros e brancos, resultando na defesa da igualdade de ofertas e condições de entrada na universidade e rejeitando qualquer medida de favorecimento aos negros. Além disso, os valores ligados ao mérito e esforço pessoal também são ressaltados, de forma a se defender a idéia de que aquele que se dedica consegue vencer barreiras e não precisa de "proteções adicionais". Por outro lado, alguns estudos mostram o apoio de certos segmentos da população brasileira a essa iniciativa, inclusive por parte de docentes que ministram aulas em instituições que já adotaram a política de cotas, os quais declaram que não houve mudanças na qualidade de ensino e que as relações raciais na universidade permaneceram iguais ou, até mesmo, melhoraram (Petrucelli; Ferreira; Brandão, 2006).

Considerando a Teoria das Representações Sociais, criada por Moscovici (1978), po- demos dizer que, no Brasil, antigas representações sociais sobre os negros, arraigadas no imaginário da população em geral, entram em choque com novas representações construídas e defendidas por militantes e simpatizantes pela luta em defesa dos direitos dos negros, assim como estudiosos do assunto, os quais têm adquirido reconhecimento e espaço na agenda política do governo brasileiro.

Uma representação antiga acerca das relações entre negros e brancos, no Brasil, é a que se refere ao "mito da democracia racial", por meio do qual se nega haver em nosso país preconceitos e discriminação de raça ao mesmo tempo em que se defende "a mestiçagem como padrão fortificador da raça” (Chauí, 2000, p. 8). Segundo esse ideário, vivemos em um país em que há a igualdade étnico-racial e que as desigualdades que ocorrem se explicam, exclusivamente, por fatores econômicos. Há igualmente uma suposta "identidade nacional" que vê o Brasil como um país de mestiços, onde há convivência pacífica e mistura de diferentes raças e etnias (Camargo, 2005a; Carvalho; Segato, 2002).

A reivindicação de cotas para negros em universidades brasileiras se coloca como uma política de ação afirmativa que tem como princípio motivador o alcance da igualdade real entre negros e brancos. Ela parte da constatação histórica das inúmeras discriminações que os negros sofreram, no Brasil, e buscam uma forma de reparação e/ou compensação das perdas causadas a esse grupo (Carvalho; Segato, 2002).

Por meio das cotas para os negros, nas universidades, pretende-se principalmente possibilitar-lhes o acesso a níveis econômicos, sociais e culturais mais elevados na sociedade, aumentando a existência de uma classe social média e alta para esse grupo, tal como aconteceu nos EUA (Guimarães, 2003a; 2003b). Silvério (2003) defende que uma das conseqüências imediatas da adoção de ações afirmativas seria a inclusão de parcelas da comunidade negra em posições estratégicas no

1. É importante ressaltar que, em razão da autonomia de que gozam as Instituições Públicas de Ensino Superior no Brasil, cada universidade tem elaborado projetos próprios para adoção das políticas de cotas. 
mercado de trabalho e nas universidades, iniciando, assim, o processo de desracialização das posições de maiores status e renda, favorecendo a construção de uma democracia sem a demarcação de grupos étnico-raciais. Além disso, a existência de negros na universidade possibilitaria modelos positivos de identificação aos demais membros desse grupo, mudando uma imagem negativa ou "lúdica" que se tem do negro no país (Ramos, 2003; Carvalho; Segato, 2002). A maior presença de negros nas universidades levaria a uma ampliação na diversidade étnico-racial nesses espaços, possibilitando outras visões de mundo e perspectivas culturais. Em termos de valores, podemos pensar que as cotas embasam-se na busca da realização do valor de igualdade aqui e agora e não apenas como promessa de direito. Por outro lado, tratam de mostrar diferenças reais entre negros e brancos, que existem há séculos, não por falta de capacidades dos negros, mas por terem sofrido toda a sorte de discriminações e interdições às mínimas condições de desenvolvimento. Por isso, o valor de justiça somado ao da igualdade é aclamado: trata-se de pedir a justiça, hoje, pela compensação de perdas sofridas no passado.

Recentemente, realizamos (Shimizu et al., 2006) uma pesquisa em que comparamos as posições de estudantes de uma universidade pública do estado de São Paulo que não adota a política de $\operatorname{cotas}^{2}$. Para o estudo, foram aplicados diferentes tipos de questionários a 403 universitários participantes, os quais objetivavam verificar se suas representações sobre esse tema variavam conforme as possibilidades de ingresso na universidade, a saber: 1) vestibular simples; 2) cursinhos para alunos carentes; 3) cotas simples ${ }^{3}$; e 4) cotas duras $^{4}$. Os estudantes fictícios, aos quais as cotas seriam destinadas, aqui chamados público-alvo da pesquisa, eram negros, afrodescendentes e alunos de escolas públicas. Na ocasião, tivemos 12 modelos de questionário, combinando as quatro formas de ingresso na universidade - vestibular simples, cursinho, cotas simples e cotas duras - e os três tipos representativos do público-alvo.

Como resultados da pesquisa de Shimizu et al. (2006), verificamos que, quanto mais as políticas ameaçavam a concorrência ao vestibular, como as cotas duras, mais foram vistas de maneira negativa, ou seja, apontadas como inconstitucionais, injustas ou até discriminatórias. Na mesma medida, mais seus supostos usuários, no caso, negros ou afrodescendentes, foram considerados negativamente como aproveitadores ou vítimas de mais discriminação. Por outro lado, constatamos, nesse mesmo estudo, que os estudantes consideraram que há um desfavorecimento real em relação aos alunos oriundos de escolas públicas (mais que entre alunos negros ou afrodescendentes) e, assim, as políticas de cotas foram mais bem admitidas para os alunos de escolas públicas que para os demais públicos-alvo. De todas as medidas, o cursinho para alunos carentes foi visto como a mais positiva ou justa e menos ameaçadora, embora certas pesquisas enfatizem a pouca eficácia real dos cursinhos em favorecer o ingresso de negros nas universidades públicas (Santos, 2004; Augusto Brandão, 2004). Outro dado importante foi identificado a partir da pertinência social e racial dos participantes da pesquisa: os estudantes negros, de menor faixa salarial, foram mais favoráveis às políticas de cotas do que os demais. Esse posicionamento deixou evidente que esse tipo de ação afirmativa é aceita por uma pequena parcela de alunos negros.

Apresentamos, no presente artigo, a análise por nós realizada das respostas dadas a uma pergunta aberta, que fizemos aos alunos, na pesquisa em foco (Shimizu et al., 2006), na qual pedimos a descrição dos alunos negros, ou afrodescendentes, ou de escolas públicas que seriam usuários das cotas, ou do cursinho gratuito para alunos carentes, ou que ingressariam na universidade pelo vestibular.

\footnotetext{
2. Essa pesquisa foi realizada na Faculdade de Ciências e Tecnologia da Universidade Estadual Paulista -Presidente Prudente (SP).

3. 0 enunciado da política foi: "Uma certa porcentagem de vagas deverá ser reservada e disputada entre os estudantes negros (ou afrodescendentes ou alunos de escolas públicas) aprovados no vestibular" (Shimizu etal., 2006). 4. Enunciado: "Uma certa porcentagem de vagas deverá ser reservada aos estudantes negros (ou afrodescendentes ou alunos de escolas públicas). Se não houver número suficiente de estudantes dessa categoria aprovados no vestibular para ocupar essas vagas, o número dos outros estudantes será reduzido para respeitar a proporção buscada" (Shimizu et al., 2006).
} 
Nosso objetivo, neste trabalho, é investigar quais valores estão mais presentes na avaliação que os estudantes fazem dos supostos usuários das cotas e se esses valores variam em função do tipo de política afirmativa que está sendo proposta ao usuário e/ou do tipo de público-alvo que delas se beneficia: negros, afrodescendentes ou alunos de escolas públicas.

0 referencial adotado neste estudo é o da Teoria das Representações Sociais, que se tem mostrado um importante recurso teóricometodológico em pesquisas de diversos campos, especialmente da área da Educação (Sousa, 2002; Arruda, 2005; Menin; Shimizu, 2005).

Representações são formas de conhecimento cotidiano, de senso comum, diferentes do conhecimento científico ou acadêmico. São nomeadas por Moscovici de "teorias, "ciências coletivas' sui generis, destinadas à interpretação e elaboração do real” (1978, p. 50).

Essa noção foi introduzida, especialmente na Psicologia Social, por Serge Moscovici (1978), quando estudou a apropriação da Psicanálise por diferentes grupos sociais, na França, nos anos 1960. Com essa investigação, Moscovici demonstrou como conhecimentos científicos - especificamente os da Psicanálise - são transformados em representações sociais. Estas, todavia, não se limitam apenas ao caminho que vai da ciência ao senso comum, são produzidas nas mais variadas interações entre o pensamento popular e o contexto social, podendo ser consideradas possíveis geradoras de representações: teorias científicas, conceitos sociais, discursos, arte, cultura, enfim, toda realidade material e ideal (Jodelet, 1986).

Tal como demonstrado por Moscovici (1978), as representações sociais são apresentadas, reconstruídas e divulgadas a partir de uma série de meios de comunicação social. A imprensa falada e escrita, a literatura, o cinema, e tantas outras formas de divulgação de conhecimento popular influem sobre o sujeito social de várias maneiras, interferindo nos modos de apropriação e construção de conhecimentos diversos.

As representações sociais, por sua origem e constituição, não são abordadas de modo genérico, mas são sempre representações de algo - um objeto, um conceito, um fenômeno socialmente implicado sobre o que se fala - e de alguém - de quem se deve saber quem fala e de onde fala. Aderir a uma representação é participar de um grupo. Quem representa, faz isso de um lugar social. É um sujeito que tem uma pertinência num grupo, numa classe ou posição social e que se relaciona com outros através de diferentes formas de comunicação, participando da construção de um mundo comum. Portanto, nos estudos de representação social, nos interessam os sujeitos coletivos, aqueles inseridos em grupos que têm um mesmo tipo de pensamento ou conhecimento (Jodelet, 1994; 2001).

\section{Aspectos metodológicos da pesquisa}

Os participantes da pesquisa foram 403 alunos da UNESP, campus de Presidente Prudente (SP), homens e mulheres de diversos cursos - Educação Física, Geografia, Matemática, Física, Arquitetura, Fisioterapia e Pedagogia - e de diferentes séries. Desse conjunto, $71,7 \%$ denominaram-se brancos; $16 \%$, negros ou pardos; 6,7\%, amarelos; e 5,3\%, de outras raças ou etnias, como indígenas, "multi-étnicos", dentre outros. 0 nível socioeconômico dos alunos foi mensurado por meio da faixa salarial paterna, sendo que 45,6\% dos alunos relataram terem pais com faixa salarial inferior a mil reais, enquanto 54,4\% revelaram ser esta superior a mil reais. A aplicação dos questionários, no que diz respeito à política e ao público-alvo, foi homogênea.

Fizemos uma análise qualitativa das respostas dadas à única questão aberta utilizada nos questionários da pesquisa de Shimizu et al. (2006), as quais examinaremos aqui. A questão foi: "Podendo descrever esses alunos negros (ou afrodescendentes, ou provenientes de escolas públicas) em algumas palavras, o que você diria?” Ela se referia a um dos públicos-alvo em cada um dos 12 modelos de questionários usados na pesquisa, em 
que se combinaram os três tipos de público-alvo (negros, afrodescendentes, alunos de escolas públicas) e as quatro políticas de ingresso às universidades (vestibular, cursinho, cotas simples e cotas duras). Assim, ao responder a essa questão aberta, os alunos estavam julgando sempre um dos públicos-alvo numa das políticas de ingresso à universidade. Anteriormente a essa questão, foram apresentadas outras, na forma de escalas de nove pontos, que questionavam os respondentes a respeito de vários aspectos sobre os critérios de ingresso nas universidades: apresentavam uma política de ingresso em particular e pediam apreciações desta em relação a vários aspectos (se é justa, se é eficaz, se é realista, se ameaça o clima da universidade etc.); perguntavam sobre a porcentagem ideal da presença do público-alvo nas universidades; solicitavam a avaliação do públicoalvo por meio de qualidades positivas e negativas apresentadas.

Como método de análise, usamos duas abordagens. Na primeira, utilizamos o ALCESTE (Analyse Lexicale par Contexte d'un Ensemble de Segments de Texte, de Max Reinert, 1990), de maneira a investigar a presença de classes de respostas e sua correlação com as políticas de ingresso na universidade e com o público-alvo ingressante. Na segunda, de modo complementar ao ALCESTE, realizamos uma análise de conteúdo, em que buscamos identificar que valores foram mais evocados pelos alunos para avaliar os usuários das políticas de cotas e para justificar suas posições favoráveis ou contrárias a estas. Mesmo mediante uma análise qualitativa, buscamos verificar se esses valores se modificam em função do público a que se referem - negros de um lado e alunos de escolas públicas de outro - ou em função da forma de ingresso nas universidades de que se beneficiariam - do vestibular às cotas.

\section{Os resultados alcançados}

A análise das respostas através do ALCESTE

Todas as respostas dos alunos foram digitadas, de sorte a serem colocadas no programa ALCESTE, acompanhadas das características dos participantes, para futura identificação de variáveis na operacionalização do programa: número do questionário, curso do respondente, público-alvo do questionário, política do questionário, sexo do respondente, cor (autodeclarada) do participante e salário do pai (autodeclarado). Segundo Veloz, Nascimento-Shulze e Camargo (1999) e Camargo (2005b), o programa ALCESTE realiza quatro etapas de análise, a saber:

- preparo do material por meio do reconhecimento das unidades de contexto inicial (UCI), que consistem, nesta pesquisa, nas próprias respostas à questão aberta. Divisão das $\mathrm{UCl}$ em segmentos de texto, denominadas unidades de contexto elementar (UCE), que são dimensionadas em função do tamanho do próprio texto ou corpus de análise e da pontuação;

- efetivação de cálculos que classificam as UCE com base nas palavras que as compõem. Essa operação é feita com auxílio de matrizes de freqüências que cruzam as palavras do vocabulário com as UCE do corpus em análise. Nessa etapa, é utilizado o método de classificação hierárquica descendente, por meio do qual as UCE são divididas em classes $^{5}$, de acordo com o vocabulário, de maneira que se atinja o maior valor possível pela prova do Qui-quadrado.

- execução de operações complementares para cada uma das classes obtidas anteriormente, com fins de descrição destas;

- fornecimento das UCE mais características, o que possibilita a contextualização de seus respectivos vocábulos.

Nesta pesquisa, o ALCESTE dividiu o corpus de análise em 338 UCE e classificou

5. Conforme Camargo (2005b), em nível de programa informático, cada classe é composta de diversas UCE, de acordo com a classificação que, por sua vez, é consoante à distribuição do vocabulário destas. No âmbito da lingüística, as classes são interpretadas como campos lexicais ou contextos semânticos. Na investigação sobre o conhecimento do senso comum, as classes podem revelar representações sociais ou campos de imagens sobre determinado objeto ou, ainda, diferentes aspectos de uma mesma representação social, conforme a especificidade de cada pesquisa. Reinert (apud Camargo, 2005b; Oliveira; Gomes; Marques, 2005) considera as classes como noções de mundo ou quadros perceptivo-cognitivos com determinada estabilidade temporal e vinculadas a um ambiente complexo. 
para análise 330, o que representa 97,63\% de aproveitamento do material.

Na Figura 1, apresentamos uma síntese dos resultados que permite a compreensão do perfil da análise com descrição de seus aspectos principais, tais como: ordem hierárquica de distinção, divisão de classes, número de UCE e porcentagem de cada classe em relação ao total, variáveis descritivas e palavras de maior associação com cada classe, conforme freqüência e Qui-quadrado.

Como resultado da análise, foram geradas cinco classes diferentes. Primeiramente, o corpus foi dividido em dois subcorpus: de um lado, aquele que sofreu uma nova partição, gerando as classes 3 e 4 , e de outro, aquele que originou a classe 2. Posteriormente, há mais uma partição que originou as classes 1 e 5. Em termos de proximidade, observamos que as classes 1 e 5 são bastante próximas, assim como as classes 3 e 4 também o são entre si. Em relação à distribuição das UCE entre as classes, que indica sua representatividade no conjunto do corpus analisado, constatamos que a classe com maior número de UCE foi a classe 3 , com 77 , correspondendo a $23,33 \%$ do total de UCE classificadas; em seguida, a classe 4 , com 74 , equivalendo a $22,42 \%$ do total; logo após, as classes 2 e 5 , com respectivamente $68(20,61 \%)$ e $64(19,39 \%)$; e com menor número de UCE está a classe 1 , composta por 47 , que corresponde a $14,24 \%$ do total. Notamos, de forma geral, que as distribuições das UCE entre as classes foram semelhantes, com exceção da classe 1 , que deteve o menor aglomerado do discurso examinado.

Focalizaremos, a seguir, os conteúdos de cada classe, no que concerne às respectivas palavras associadas e apresentaremos algumas das UCE características, que são consideradas representativas de cada classe e indicativas do contexto de significação das palavras associadas.

$\mathrm{Na}$ classe 2, as palavras que se associaram com maior força [freqüência maior que 6 e

Figura 1: Dendograma resultante da classificação hierárquica do material textual analisado.

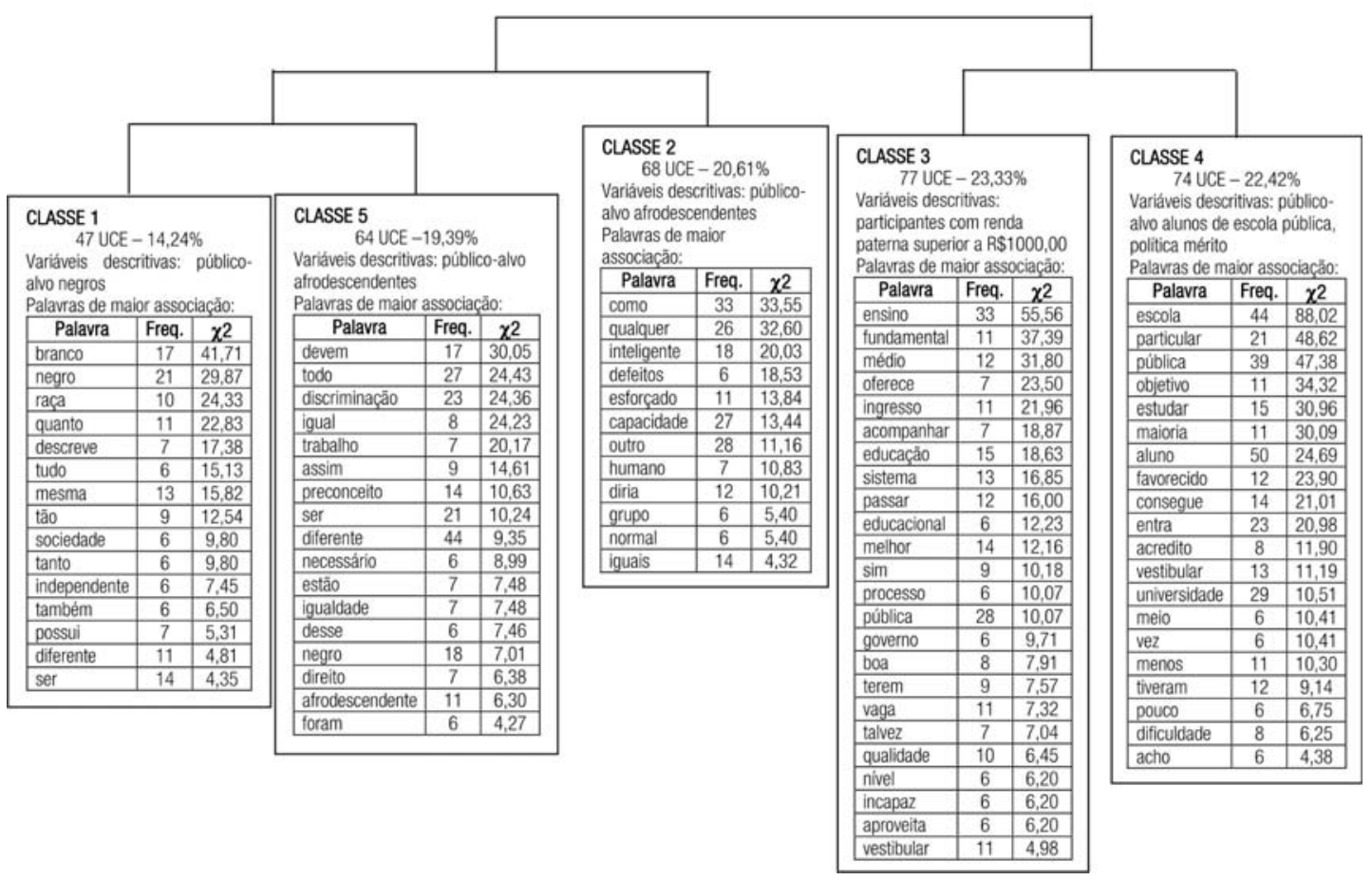


Qui-quadrado maior ou igual a 3,84, segundo Camargo (2005b)] a essa classe foram: como, qualquer, inteligente, defeitos, esforçado, capacidade, outro, humano, diria, grupo, normal e iguais; compondo o sentido de igualdade entre as pessoas. A variável descritiva da classe foi 0 público-alvo afrodescendentes, o que indica que a maior parte das UCE características da classe foi produzida por aquelas pessoas que tinham os afrodescendentes como beneficiários das políticas aos quais seus respectivos questionários se reportavam. Alguns exemplos das frases mais características dessa classe foram:

São seres humanos como qualquer outro, dotados de capacidade, inteligência e tudo mais. (Aluna da Pedagogia, parda, públicoalvo afrodescendentes, política cotas duras, salário paterno inferior a mil reais)

Diria que todos eles têm capacidade como qualquer outro aluno, mas que eles seriam discriminados por terem entrado através de cotas, e não por mérito próprio. (Aluna de Engenharia Florestal, branca, público-alvo afrodescendentes, política cotas duras, salário paterno inferior a mil reais)

Bom, eu diria que esses alunos afrodescendentes têm o mesmo potencial que os outros alunos, no entanto eles mesmos se sentirão discriminados diante deste caso. Capacidade todos têm... e inteligência também... (Aluna de Matemática, branca, públicoalvo afrodescendentes, política cursinho, salário paterno superior a mil reais)

Portanto, nessa classe, o valor que mais surge é o da igualdade entre brancos e negros, negando-se qualquer diferenciação, seja para favorecê-los, seja para discriminá-los. Poucas respostas incluídas nessa classe se referem às cotas e aquelas que o fazem consideram-nas desnecessárias ou discriminatórias, uma vez que se tem como representação predominante a crença na igualdade em relação àqueles atributos considerados importantes para o ingresso na universidade: inteligência, esforço, força de vontade, capacidade, dentre outros.

A classe 4 teve como palavras mais freqüentes e de maior Qui-quadrado, em ordem decrescente: escola, particular, pública, objetivo, estudar, maioria, aluno, favorecido, consegue, entra, acredito, vestibular, universidade, meio, vez, menos, tiveram, pouco, dificuldade, acho. Os participantes que mais se associaram a essa classe foram, primeiramente, os respondentes dos questionários que tinham como público-alvo os alunos de escola pública e, em segundo lugar, a política de mérito. Essa classe enfatiza a concorrência para o ingresso na universidade entre alunos de escolas públicas e particulares; o favorecimento dos alunos provenientes de escolas particulares; e o esforço e força de vontade dos alunos das escolas públicas. Ressalta, em muitas respostas, o esforço, o mérito, e a força de vontade pessoal como valores fundamentais. Indica, ainda, em algumas respostas, o temor da queda de qualidade da universidade com o ingresso de alunos menos preparados. Exemplos de frases características:

Os alunos de escola pública são, em geral, menos favorecidos em relação aos das escolas particulares, tendo que recorrer a cursinhos pré-vestibulares, isso quando têm condições de pagar. (Aluna de Matemática, branca, público-alvo alunos de escola pública, política mérito, salário paterno inferior a mil reais)

Alunos que foram favorecidos por meio de cotas e que, na maioria das vezes, não obtiveram conhecimento suficiente para entrar na universidade, mas são alunos com vontade e determinação. Mas, dessa forma, o nível da universidade poderia cair. (Aluno de Matemática, branco, público-alvo alunos de escola pública, política mérito, salário paterno superior a mil reais)

Que são alunos como os de escolas particulares e que, se entrarem em uma universidade pública, é porque foram merecedo- 
res. (Aluna de Fisioterapia, branca, públicoalvo alunos de escola pública, política mérito, salário paterno superior a mil reais)

Geralmente, o aluno de escola pública sai meio desencorajado para prestar vestibular, devido já ter ouvido várias vezes que alunos de escolas públicas não conseguem entrar em universidades. Mas, quando conseguem, se revelam muito inteligentes e interessados, porque sabem da dificuldade que enfrentou para estar ali. (Aluna de Pedagogia, branca, público-alvo alunos de escola pública, política cursinho, salário paterno inferior a mil reais)

Portanto, nessa classe, os valores que sobressaem na descrição dos beneficiários são o esforço pessoal, a força de vontade, o mérito pessoal, apesar da diferença apontada pelos respondentes do nível do ensino entre a escola pública e a particular. Em conseqüência, fica marcante, nessa classe, a representação de que a concorrência entre um aluno de escola pública e um de escola particular é bastante desigual e que, somente com muito esforço, força de vontade ou até mesmo "sorte" ou "milagre", o aluno de escola pública consegue passar no vestibular. Nas poucas vezes em que os respondentes que se associaram a essa classe se referiram às cotas, colocaram-se contrários, justificando que o ingresso por meio dessa política poderia prejudicar a qualidade do ensino na universidade pública, uma vez que os alunos provenientes do ensino público não estariam adequadamente preparados para acompanhar o curso.

A classe 3 teve como palavras típicas aquelas que se referem a melhoramentos no ensino: ensino, fundamental, médio, oferece, ingresso, acompanhar, educação, sistema, passar, educacional, melhor, sim, processo, pública, governo, boa, terem, vaga, talvez, qualidade, nível, incapaz, aproveita, vestibular. Os respondentes que mais se associaram a essa classe foram aqueles com renda paterna superior a mil reais. Exemplos de afirmações:
As reformas de Ensino Fundamental e Médio são as saídas para uma universidade igualitária. 0 sistema de cotas é um "instrumento burro", incapaz de somar os verdadeiros problemas. Assim, um aluno que passou através deste cursinho soube aproveitar uma oportunidade válida e correta, ao contrário da hipótese de passar mediante o sistema de cotas, que é protecionista e preconceituoso. (Aluno de Matemática, branco, público-alvo alunos de escola pública, política cursinho, salário paterno superior a mil reais)

Diria que os negros são discriminados no Brasil. 0 país usa uma máscara do preconceito e procura mostrar a falsa igualdade, quando os negros são vitimas de preconceito, e como os pobres em geral merecem uma atenção especial do governo pelo menor curto prazo, mas de nada adiante uma cota, sem um bom ensino, uma "bagagem intelectual" para as pessoas. (Aluno de Geografia, negro, público-alvo negros, política cotas, salário paterno superior a mil reais)

Que são alunos vítimas da falta de qualidade no ensino público fundamental e médio. (Aluna de Engenharia Florestal, branca, público-alvo alunos de escola pública, política cotas, salário paterno superior a mil reais)

Os cotistas, nessa classe, são apresentados ora como beneficiados pelas cotas, ora como discriminados por condições passadas e merecedores de cotas, porém é comum a quase todas as respostas ser favorável, não às cotas, mas à igualdade de acesso a um sistema justo de ensino. A igualdade que se defende aqui é aquela da oferta de condições de educação bem qualificada a todos, sem diferenciação. Culpa-se o governo pelo descaso com a escola pública.

A classe 5 tem como palavras de maior força de associação aquelas que destacam os deveres relacionados à igualdade e aos riscos da discriminação racial decorrente do próprio 
sistema de cotas: devem, todo, discriminação, igual, trabalho, assim, preconceito, ser, diferente, necessário, estão, igualdade, desse, negro, direito, afrodescendente, foram. A variável que mais se aproximou dessa classe foi o públicoalvo afrodescendentes. Algumas das respostas características dessa classe foram:

Eu diria que os afrodescendentes são pessoas como nós, sendo assim, todos devem ter os mesmos direitos, serem tratados com igualdade e respeito. Todas as pessoas devem ter os mesmos tratamentos e devem ser admitidos nas universidades com os mesmos direitos e privilégios que qualquer um. Eles são pessoas de bem como qualquer um de nós. (Aluna de Matemática, branca, públicoalvo afrodescendentes, política cursinho, salário paterno inferior a mil reais)

Não é o fato de serem afrodescendentes que identifica essa necessidade de concorrer a uma vaga apenas com outros afrodescendentes: isso seria afirmar que esses alunos não têm condições intelectuais de concorrer com os outros. Além disso, esse método viria a segregar ainda mais esses dois grupos, que deveriam ser diferenciados, pois na verdade é apenas um grupo, ou pelo menos deveria ser. (Aluna de Geografia, branca, público-alvo afrodescendentes, política cotas, salário paterno inferior a mil reais)

O Brasil tem uma grande dívida com o povo que mais contribuiu com o crescimento do país, os negros. Porém, cotas será apenas uma medida paliativa e não acabará com o problema. A educação deve começar na base, desde os primeiros anos até a fase pré-vestibular, assim todos terão oportunidades iguais, a cota só aumentará esta separação de cor e aumentará o preconceito, os professores terão que trabalhar com dois grupos com diferentes conhecimentos. Os negros têm capacidade de competirem de igual para igual, desde que tenham oportunidade. (Aluno de Geografia, branco, público-alvo negros, política cotas duras, salário não declarado)

De novo, o valor da igualdade comparece para defender, não as cotas, vistas aqui como um favorecimento desnecessário perigoso, pois discriminatório, mas a igualdade de tratamento ou de direitos e, portanto, de forma de ingresso na universidade. Mesmo quando se reconhece que o Brasil tem uma grande dívida com o povo negro, como nessa última resposta, a idéia de cota, como reparação necessária, apareceu somente uma vez entre as respostas dessa classe, no seguinte exemplo:

São iguais a todos nós, portanto, têm os mesmos direitos. Porém, são as maiores vítimas do processo histórico, sendo as cotas uma medida para se reparar essa contradição. (Aluna de Geografia, "rosa”, públicoalvo afrodescendentes, política cotas duras, salário paterno superior a mil reais)

A classe 1 , com base no número de UCE que a compôs, em comparação às demais classes, demonstrou ser a menos compartilhada pelos participantes da pesquisa. Contribuíram mais com essa classe os respondentes que tinham como foco, em seus respectivos questionários, o público-alvo negros. As palavras mais relacionadas foram aquelas que ressaltam a individualidade de cada um, mostrando a dificuldade em descrever pessoas em função de sua cor ou etnia, ou a igualdade, em termos de capacidades, ou de características de personalidade entre brancos e negros ou, ainda, que podem diferenciá-los apenas em termos de nível socioeconômico: branco, negro, raça, quanto, descreve, tudo, mesma, tão, sociedade, tanto, independente, também, possui, diferente. Exemplos de afirmações:

Eu diria que eles, a primeiro momento, provêm das classes sociais desfavorecidas pela atual sociedade. Portanto, pobres, com baixo nível de escolaridade. (Aluno de Geografia, branco, público-alvo negros, política 
cotas duras, salário não declarado)

Os negros são tão capazes quanto os brancos, tudo que um branco pode dentro de uma sociedade um negro também pode. (Aluno de Geografia, branco, público-alvo negros, política mérito, salário paterno inferior a mil reais)

É difícil descrever um aluno negro nesta situação, visto que cada um possui sua individualidade, e as pessoas são diferentes umas das outras, independente de serem brancos ou negros. Eu penso que este aluno não estaria tão bem preparado para enfrentar a faculdade quanto um outro aluno que enfrentou uma concorrência maior, mas vejo também que este aluno negro aproveitaria ao máximo esta oportunidade, chegando a ser um excelente profissional, depende da pessoa. (Aluna de Fisioterapia, branca, público-alvo negros, política cotas duras, salário paterno superior a mil reais)

No início iriam gostar, mas com o tempo voltariam a se acharem discriminados, agora, por terem "vagas garantidas", e isso levaria a aumento da discriminação entre negros e não negros, brancos, índios, amarelos etc. (Aluno de Matemática, branco, público-alvo negros, política cotas duras, salário paterno superior a mil reais)

Assim, as respostas dessa classe destacam a igualdade entre brancos e negros, de capacidades e de direitos, mas também a individualidade de cada e a dificuldade de descrevê-los como classe. Por outro lado, em muitos depoimentos, associase o negro ou o afrodescendente à pobreza, explicando sua dificuldade no vestibular como resultado da falta de oportunidades e chances. Portanto, explica-se o problema da ausência do negro nas universidades como um problema social, de pobreza. As cotas são vistas, na maioria das respostas, como desnecessárias ou inconvenientes, pois os respondentes acreditam que elas podem gerar mais discriminação sobre os que delas se beneficiam.

\section{A análise qualitativa das respostas}

Retomemos, aqui, à pergunta que foi respondida pelos alunos: "Podendo descrever esses alunos (negros ou provenientes de escolas públicas) em algumas palavras, o que você diria?"

Para realizar a análise qualitativa das respostas a essa questão aberta, consideramos cada conjunto dos 12 modelos de questionário relacionados a uma mesma política (vestibular, cotas ou cursinho) para cada um dos públicos-alvo (negros $^{6}$ e alunos de escolas públicas). Assim, apresentamos, a seguir, as categorias de respostas que se sobressaíram, quando pedimos aos universitários que avaliassem os negros, se estes ingressassem na universidade por vestibular; depois, os alunos de escolas públicas, se ingressassem no vestibular; a seguir, os negros, quando cotistas; depois, os alunos de escolas públicas, quando fossem cotistas; os negros, quando ingressassem na universidade por meio da ajuda de um cursinho específico; e por último, os alunos de escolas públicas, também auxiliados pelo cursinho.

Lembramos que um mesmo conjunto de alunos respondente analisava somente um tipo de questionário para um tipo de público-alvo ${ }^{7}$. Não examinamos, nesta análise, os questionários que ofereceram como cenário a política afirmativa de cotas duras, uma vez que essa política não existe no Brasil e a consideramos, portanto, artificial.

\section{Quando os alunos ingressam na universidade por meio do vestibular}

Foram 104 os participantes que responderam ao questionário relativo ao ingresso na universidade pública pelo vestibular - processo seletivo ainda utilizado na maioria das universidades brasileiras -, sendo que 69 deles tinham como público-alvo negros e 35 , alunos de esco-

6. Na pesquisa anterior de Shimizu et al. (2006), foram utilizados os dois públicos-alvo: negros e afrodescendentes. Como não houve diferenças entre eles, nesta análise, empregaremos somente a nomenclatura negros.

7. Cada público-alvo combinado com cada política teve, no mínimo, 30 alunos respondentes, provindos de cursos variados, sendo aleatória a presença de alunos autodeclarados negros ou brancos em cada conjunto. 
la pública. Dentre os primeiros, 24 participantes não responderam à questão abordada neste estudo; e em relação aos seguintes, 7 participantes não a responderam. Dessa forma, analisamos as respostas de 45 estudantes que tinham como foco os negros e 28 que possuíam como alvo alunos de escola pública.

Ao descreverem os negros que ingressassem na universidade por meio do vestibular, os participantes revelaram três tipos de posicionamentos predominantes: a defesa de que todos são iguais, embora com alegações dos mais diversos aspectos que sustentam a noção de igualdade adotada; a atribuição de características positivas aos ingressantes, relacionadas a valores pessoais e individuais; e, por fim, a disposição explicitamente contrária à política de cotas, pautada nos mais variados fundamentos.

0 primeiro posicionamento foi o mais mar-cante, uma vez que 22 , dentre os 45 universitários (49\%), o defenderam. Segundo esses alunos, os negros são iguais aos brancos e, em decorrência, diferentes argumentos são usados para justificar uma posição contrária às cotas. Consideram, por exemplo, que os negros possuem as mesmas capacidades que os brancos e, por isso, não se justificam cotas. Ou, se todos são iguais, entendem que o ingresso na universidade é uma questão de esforço pessoal e não de diferenças de cor ou sociais; ou, ainda, mesmo se admitindo discriminações passadas, entendem que o esforço pessoal pode superar as dificuldades antes colocadas aos negros.

Num segundo tipo de posicionamento, a idealização do valor pessoal de cada um é muito ressaltada entre os participantes ( 6 dos 45 respondentes, ou seja, 13,3\% do total), os quais atribuíram aos negros que ingressam na universidade pelo vestibular qualidades como as de serem estudiosos, esforçados, merecedores, capazes, lutadores, vencedores e determinados.

0 terceiro grupo de categoria de respostas foi daqueles participantes que se posicio-naram, declaradamente, contrários a qualquer tipo de favorecimento aos negros para o ingresso nas universidades, mesmo nessa parte do estudo que só se referia ao vestibular. A justificativa mais presente ( 5 alunos, $11,1 \%)$ foi a de que a entrada desse público por meio da política de cotas aumentaria o preconceito racial e a discriminação em relação a eles, pois passariam a ser vistos como diferentes, não capazes ou não merecedores, uma vez que não estariam concorrendo em condições de igualdade.

Nos julgamentos concernentes aos alunos de escola pública admitidos pelo vestibular, pudemos identificar que algumas categorias de respostas foram semelhantes àquelas reconhecidas na análise sobre os negros, como a defesa de que todos são iguais (dadas por 4 dos 28 respondentes, 14,2\%), com o uso de diferentes argumentos que devem fundamentar essa igualdade; a imputação de características positivas aos ingressantes, relacionadas às qualidades individuais, realizada por seis participantes $(21,4 \%)$; a disposição contrária à política de cotas (4 universitários, 14,2\%). Houve, ainda, aquelas respostas que apareceram, anteriormente, de forma pulverizada e que agora reaparecem com mais representatividade, como as de que não é possível descrevê-los (2 participantes, 7,1\%) e de que a qualidade da escola pública está muito ruim (4 deles ou 14,2\%).

Além disso, um número considerável de participantes (7 respondentes, equivalente a 25\% do total em foco) descreveram os alunos de escolas públicas como pessoas desfavorecidas pelas condições de desigualdade social, econômica e educacional. Salientaram que, se conseguem passar no vestibular, é porque superam essas adversidades, as dificuldades inerentes e sobrevivem diante das injustiças sociais.

Por fim, tivemos um único participante que, de acordo com a sua resposta, expressou sua posição favorável à política de cotas, ressaltando que os alunos de escola pública não possuem muitas oportunidades, por isso, não poderiam ser julgados como oportunistas ou aproveitadores. No entanto, segundo o respondente, essa medida não seria suficiente para reparar a história de discriminação sofrida por eles. 


\section{Quando os alunos ingressam por meio das cotas}

Os julgamentos que os universitários fizeram a respeito dos alunos negros ingressantes numa universidade por cotas podem ser resumidos em três posições-chave: aqueles que se mostraram neutros, não se posicionando em relação aos cotistas de maneira favorável ou desfavorável; aqueles claramente favoráveis aos cotistas, dizendo-os merecedores das cotas por diferentes motivos; e aqueles claramente contrários. As atitudes em relação aos alunos negros cotistas rechearam-se de valores e de "representações normativas" (Doise, 2001, p. 10) em busca de justificações das posições tomadas pelos universitários. Relevante notar que os mesmos valores, como a igualdade e a justiça, foram usados tanto para justificar uma posição favorável aos cotistas como a posição contrária.

Duas categorias bastante freqüentes entre os respondentes, que estamos chamando de "neutras", avaliaram os ingressantes cotistas negros como iguais a qualquer outro aluno, com as mesmas capacidades, qualidades ou defeitos; ou, ainda, negaram-se a atribuir julgamentos, apontando a individualidade de cada indivíduo e a injustiça de tecer julgamentos baseados no pertencimento a um grupo em função da cor de pele ou da categoria cotista. lguais aos outros ou indivíduos únicos, como os outros, essas respostas não levaram a um posicionamento do respondente favorável ou contrário às cotas e representaram 21 ocorrências em 62 alunos respondentes (33,5\%).

Um segundo conjunto de categorias mais freqüente foi aquele em que os respondentes se colocaram, por diferentes motivos, contrários à política das cotas, apontando diferentes apreciações a respeito dos cotistas e de seus direitos e condições de ingresso na universidade (28 respostas em 62 alunos, 45\%): o uso da cor como maneira de passar no vestibular e não o mérito próprio; o reconhecimento de um desfavorecimento causado por motivos sociais e de escolarização e não ligado à cor; as cotas vistas como medida discriminatória, colocando os negros como inferiores e trazendo o perigo de maior discriminação.

Finalmente, numa posição favorável às cotas, apareceram as respostas que fizeram julgamentos elogiosos aos alunos negros cotistas, ressaltando suas qualidades de esforço pessoal e de resistência, tal como: "lutadores" ou "batalhadores" ( 6 alunos ou 9,5\%) e seu direito na conquista de vagas na universidade em função dos séculos de discriminação; sendo, portanto, justificável a política de cotas por uma questão de reparação histórica (4 alunos ou 6,5\%). Somadas, essas respostas correspon-deram às afirmações de 10 alunos em 62 (16\% dessa população).

Quando os alunos de escolas públicas são os cotistas, vimos uma mudança de atitudes dos participantes da pesquisa. Os julgamentos passaram a ser mais favoráveis ou mais tolerantes à política das cotas. Nessa perspectiva, surgiram 50\% de respostas claramente favoráveis aos cotistas, que foram vistos como esforçados e capazes ( 11 alunos em 30 respondentes ou $36,6 \%$ ) ou desfavorecidos, pela falta de oportunidades escolares, provocadas por um governo negligente, que não lhes propiciou uma boa escola (4 ou 13\%).

Houve, ainda, argumentos neutros em relação às cotas (4 alunos em 30 ou 13\%), nos quais os alunos afirmaram que pré-julgamentos são preconceituosos ou que há igualdade dos cotistas de escolas públicas em relação a qualquer outro aluno.

Os argumentos contrários às cotas ou aos cotistas de escolas públicas, que foram 10 respostas entre as $30(33,33 \%)$, centraram-se na crítica à qualidade da escola pública fundamental e média, entendendo, portanto, que é ela quem deve melhorar, para todos, e a solução não seria buscar-se sanar o problema com cotas.

\section{Quando os alunos ingressam na universidade por meio do cursinho gratuito}

Quando os julgamentos de nossos respondentes se referiram aos alunos negros pro- 
vindos de cursinhos gratuitos reservado a eles, atitudes, valores e representações sobre estes foram, freqüentemente, positivas: das 57 respostas que tivemos, nesse modelo de questionário, 29 (50\%) foram claramente a favor desse público-alvo. Os argumentos favoráveis mais pronunciados se referiram às características de capacidade e esforço, força de vontade e luta por uma oportunidade; ou, ainda, saber aproveitar bem uma oportunidade, como o cursinho, quando ela se apresenta (14 respostas ou 24\%). 0 próprio cursinho foi apontado como uma boa alternativa, que não gera discriminação (3 respostas ou 5\%). Outro argumento lembrou a história de vida dos negros, marcada pelo preconceito e discriminação, valorizando-os como lutadores e merecedores da oportunidade do cursinho gratuito (6 respostas ou 10,5\%). Houve, também, julgamentos muito centrados no valor pessoal de cada um, na força de vontade individual, além da afirmação de que não há diferenças entre brancos e negros, porém que tudo é questão de luta pessoal (3 respostas ou 5\%).

Continuaram a existir respostas que evitaram exibir julgamentos de valor em relação aos alunos negros (6 respostas em 57 ou $10,5 \%$ ), afirmando a individualidade de cada um ou a igualdade de todos, independentemente da cor ou do fato de poder usufruir de uma política afirmativa.

Existiram, ainda, julgamentos depreciativos em relação aos alunos negros que usufruiriam dos cursinhos gratuitos (20 respostas ou 35\%), nos quais se declarou: que os alunos negros vindos dos cursinhos gratuitos teriam dificuldade de acompanhar a universidade, pois apresentariam defasagens de nível de ensino ou dificuldades de aprendizagem; que foram favorecidos por usufruir dessa vantagem (o cursinho gratuito) em relação a outros que não puderam tê-la; ou, ainda, que tornam a falar que qualquer tipo de cota é uma forma de discriminação e causam um sentimento de ser discriminado. Finalmente, numa última avaliação, foi dito que os alunos negros que se beneficiaram do cursinho teriam problemas educacionais, como quaisquer alunos de baixa ren- da, pois os dois tipos vieram de um mau ensino público. Sendo assim, o problema não deve ser solucionado em função da cor dos alunos, mas em função da educação recebida.

Os julgamentos a respeito de alunos de escolas públicas vindos de cursinhos gratuitos dedicados a eles foram, praticamente, em sua totalidade, positivos. Somente 3 respostas em 31 (9,6\%), nesse modelo de questionário, fizeram certas reservas a esse público-alvo e as descreveremos adiante. Seis respondentes (6 em 31 ou 19\%) afirmaram a igualdade entre alunos da escola pública em relação a qualquer outro aluno, mas alguns destes destacaram a importância do empenho pessoal e da força de vontade no fato de se conseguir ser bem-sucedido.

As representações positivas a respeito dos alunos de escolas públicas vindos de cursinhos gratuitos ressaltaram, invariavelmente, dois aspectos: o desfavorecimento desses alunos em termos de suas bases de ensino, consideradas fracas e insuficientes para competir no vestibular com quem fez escolas particulares; e suas origens em classe econômica baixa, resultando em várias sortes de dificuldades. Algumas vezes, falou-se, igualmente, do desânimo e da falta de perspectivas dos alunos de escolas públicas, sobre seu futuro, em função das dificuldades sofridas. Em segundo lugar, as representações ressaltaram as qualidades e os valores pessoais dos alunos, pois, apesar das dificuldades, mantêm-se estudando e aproveitam as oportunidades. São, portanto, alunos esforçados, merecedores, inteligentes, capazes: 22 respostas entre as 31 foram assim (71\%).

As poucas categorias que apresentaram algum julgamento negativo, em relação aos alunos de escolas públicas vindos de cursinhos gratuitos, fizeram ressalvas às cotas, considerando o cursinho uma maneira ainda discriminatória, valorizando apenas o mérito próprio do aluno como a única forma legítima de ingresso no vestibular. Ou, então, apontaram que, por vezes, o aluno da escola pública pode ser desrespeitoso e desinteressado.

Concluímos, portanto, que o público-alvo e a política de ação afirmativa mais favoravelmente 
avaliados pelos universitários, nesta pesquisa, foram os alunos de escolas públicas ingressantes nas universidades por meio de cursinhos gratuitos.

\section{Considerações finais}

Os resultados desta pesquisa aproximamse, sob vários aspectos, de resultados de investigações já realizadas sobre cotas para negros na universidade brasileira. Nesse sentido, destacamos, a seguir, pontos convergentes entre a nossa pesquisa e aquelas comentadas na primeira parte deste trabalho.

Um primeiro ponto convergente referese ao reconhecimento da discriminação aos pobres e à negação da discriminação ou racismo contra os negros, no país, o que nos leva a pensar que o "mito da democracia racial" constitui um forte elemento na representação e negação do preconceito racial, aspecto que, segundo Santos (2003), impede

[...] uma discussão séria, franca e profunda sobre as relações raciais brasileiras e, mais do que isso, inibe a implementação de políticas públicas específicas para negros. (p. 87)

0 segundo ponto, nessa convergência, pode ser encontrado na rejeição às políticas relacionadas às cotas, que foram percebidas como mais ameaçadoras do que aquelas referentes ao mérito e cursinho gratuito. Confirmam-se, por conseguinte, pesquisas realizadas no Brasil que registram representações positivas em relação aos cursinhos para alunos negros ou carentes, como forma de ação positiva, e resistências e representações negativas à política de reservas de vagas por meio de cotas.

Os resultados concernentes às conseqüências positivas das medidas afirmativas para certos grupos e à favorabilidade de suas respectivas implementações aproximam-se, também, de pesquisas feitas no país, em que os estudantes, na maioria, são mais favoráveis às políticas mais brandas e universalistas. Há uma atitude mais propensa a admitir a política de cotas, quando se tem como beneficiários os alunos de escolas públicas. Esses resultados confirmam os argumentos de Lorenzi-Cioldi (2002) e Lorenzi-Cioldi e Buschini (2005), segundo os quais as políticas afirmativas são mais aceitas, quando direcionadas a grupos mais amplos, com baixo nível socioeconômico, do que quando beneficiam grupos mais restritos, marcados por diferenças étnicas ou raciais.

Em grande parte das respostas dadas pelos alunos, fica evidente o conflito de valores - mérito versus igualdade compensatória. Para a maioria dos respondentes, devem prevalecer os valores do mérito no ingresso no Ensino Superior. Este constitui, para eles, o sistema mais justo para ingresso de negros e alunos de escola pública na universidade. A partir da análise das respostas dadas pelos alunos, acreditamos que estamos presenciando o questionamento de valores até então considerados justos nas políticas de acesso à universidade.

Assim, valores como justiça, igualdade, esforço próprio (mérito), sobre os quais a maioria dos universitários respalda suas respostas opondo-se às cotas, estão sendo questionados pelas políticas de ação afirmativa. A nosso ver, trata-se de um conflito entre valores, em que o sistema de ingresso no Ensino Superior é visto por parte da sociedade - pelo movimento negro, em suas diferentes organizações representativas, por intelectuais e alguns políticos - como um sistema excludente e injusto, que deixa fora da universidade negros e pobres, tendo como justificativa o pressuposto da justiça do mérito e o princípio oitocentista da igualdade dos indivíduos perante a lei. Na nossa leitura, a resistência às cotas por parte dos alunos se fundamentou, principalmente, nessas duas perspectivas.

A idéia de mérito, em nossa cultura liberal, parte do pressuposto da igualdade formal dos indivíduos perante a lei. Postos nesses termos, o direito ao acesso a um emprego digno, à educação, aos serviços sociais e oportunidade de consumo passam a figurar como uma questão de mérito individual, portanto, dependente do esforço pessoal, da disciplina e dedi- 
cação de cada um. Nessa perspectiva do mérito e da igualdade formal, mantém-se o tratamento igual para aqueles que são desiguais, o que, sem dúvida, amplia as desigualdades. As políticas de ação afirmativa e a reivindicação de uma igualdade compensatória para grupos historicamente discriminados, como é o caso dos negros no Brasil, vêm se contrapor a esse ideário. 0 que se reivindica, portanto, é uma igualdade material ou substantiva, que leve em conta as discriminações sofridas por esses indivíduos ao longo da história, as quais os colocam em desvantagem econômica, bem como impõem sérios limites ao acesso à educação e ao emprego, na atualidade. Assim, a igualdade compensatória, decorrente dessas políticas, tem como preocupação geral garantir, por meio de medidas compensatórias, que os grupos discriminados tenham acesso a esses bens, visto que eles, ainda, sofrem no presente as conseqüências da discriminação e do preconceito raciais. Em conseqüência, não se trata mais de uma questão de mérito ou aplicação formal do princípio da igualdade perante a lei, mas de reparar injustiças históricas que, de outro modo, não poderiam ser sanadas ou amenizadas. As estatísticas têm demonstrado, a cada censo, que a população negra é a que menos tem tido acesso à educação, sobretudo à superior, e onde se concentram os maiores índices de pobreza e miséria, quando comparada com a população branca.

A partir do exposto, podemos dizer que enfrentar a ideologia do mérito e da igualdade de todos perante a lei parece ser mesmo o grande desafio posto às políticas de ação afirmativa. Observa-se, como vimos, o conflito entre valores em que, de um lado, está a idéia de justiça fundamentada no princípio da igualdade e do mérito e, do outro, uma noção de justiça compensatória, cujo objetivo é, conforme Santos (2003), reparar, compensar e corrigir a discriminação racial sofrida no passado por grupos sociais e que, ainda, os afetam no presente, colocando sérios limites ao desenvolvimento psicológico, social, econômico e cultural desses indivíduos.

Esse conflito de valores se dá, também, no âmbito do debate jurídico contemporâneo. Se, por um lado, há aqueles que dizem que as cotas são inconstitucionais, vamos encontrar especialistas no Direito que exploram "brechas" na Constituição Brasileira, argumentando favoravelmente à sua constitucionalidade. No artigo " 0 debate constitucional sobre as ações afirmativas”, Gomes (2003) retoma, de maneira cuidadosa, os argumentos daqueles que fundamentam a legitimidade das cotas, reportando-se a vários artigos da Constituição. Portanto, esse conflito não se situa apenas no plano das representações sociais, mas lança suas raízes no âmbito mesmo do Direito Constitucional Brasileiro.

Finalmente, é preciso assinalar a pequena presença, entre os universitários pesquisados, de representações e argumentos baseados na história do negro, no Brasil, como aqueles sobre as discriminações impostas a eles e a compensação de perdas sofridas na defesa de políticas de ações afirmativas. Esses argumentos são centrais na concepção de justiça compensatória e na consideração das condições de igualdade formal e desigualdade real, de sorte que poderiam ser contemplados em diferentes processos culturais e educacionais. 


\section{Referências bibliográficas}

ALCESTE version 4.8 pour Windows. Toulouse: Image, 2005. 1 CD-Rom.

ARRUDA, A. Pesquisa em representações sociais: a produção em 2003. In: MENIN, M. S. S; SHIMIZU, A. M. (Org). Experiência e representação social: questões teóricas e metodológicas. São Paulo: Casa do Psicólogo, 2005. p. 59-92.

AUGUSTO BRANDÃO, A. Avaliando um pré-vestibular para negros. In: REUNIÃO DA ASSOCIAÇÃO NACIONAL DE PÓS-GRADUAÇÃO E PESQUISA EM EDUCAÇÃO - ANPEd, 27., 2004, Caxambu. Anais... Caxambu: ANPED, 2004. 1 CD-ROM.

CAMARGO, E. P. R. 0 negro na Educação Superior: perspectivas das ações afirmativas. 2005. Tese (Doutorado)- Universidade Estadual de Campinas. Campinas, 2005a.

CAMARGO, B. V. ALCESTE: um programa informático de análise quantitativa de dados textuais. In: PAREDES, A. S. P. M. et al. (Orgs.). Perspectivas teórico-metodológicas em representações sociais. João Pessoa: Ed. UFPB, 2005b. p. 511-539.

CARVALHO J. J. E; SEGATO, R. L. Uma proposta de cotas para estudantes negros na Universidade de Brasília. Versão revisada e ampliada do texto preparado para a sessão do CEPE de 8 de março de 2002. Brasília, 2002.

CHAUI, M. Brasil: mito fundador e sociedade autoritária. São Paulo: Fundação Perseu Abramo, 2000.

DOISE, W. Droits de L'Homme et force dês idées. Paris: PUF. 2001.

GOMES, J. B. 0 debate constitucional sobre as ações afirmativas. In: SANTOS, R. E.; LOBATO, F. (Orgs.). Ações afirmativas: Políticas públicas contra as desigualdades raciais. Rio de Janeiro: DP\&A, 2003.

GUIMARÃES, A. S. A. 0 acesso de negros às universidades públicas. Revista da FAEEBA, Educação e contemporaneidade, Salvador, v. 12, n. 19, p. 191-204, 2003a.

0 acesso de negros às universidades públicas. In: GONÇALVES e SILVA, P. B.; SILVÉRIO, V. R. Educação e ações afirmativas: entre a injustiça simbólica e a injustiça econômica. Brasília: Instituto Nacional de Estudos e Pesquisas Educacionais Anísio Teixeira, 2003b. p. 193-216. Disponível em: <http://www.inep.gov.br/download/catalogodinamico/titulosavulsos/2003/ acoesafirmativas.pdf>. Acesso em: 05 jan. 2006.

JODELET, D.(Org.) Representações sociais. Rio de Janeiro: UERJ, 2001.

JODELET, D. Représentations sociales: un domaine en expansion. In: JODELET, D. (Org.). Les représentations sociales. 4 ed. Paris, Presses Universitaires de France, 1994. (Sociologie d'Aujourd'hui).

JODELET, D. La représentacion social: fenómenos, concepto y teoria. In: MOSCOVICI, S. Psicologia social: pensamiento y vida social. Barcelona: Paídos, 1986. v. 2, p. 469-494.

LORENZI-CIOLDI, F. La discrimination positive. Les représentations des groupes dominants et dominés. Colletions et agrégats. Grenoble: Presses Universitaires de Grenobles, 2002. p. 217-269.

LORENZI-CIOLDI, F.; BUSCHINI, F. Vaut-il mieux être une femme qualifiée ou être qualifiée de femme? Effects paradoxaux de la catégorisation dans la discrimination positive. In: SANCHEZ-MAZAS, M.; LICATA, L. L'Autre. Regards psychosociaux. Grenoble: Presses Universitaire de Grenoble, 2005. p. 279-308.

MENIN, M. S. S.; SHIMIZU, A. M. Educação e representação social: tendências de pesquisas na área - período de 2000 a 2003. In: MENIN, M. S. S.; SHIMIZU, A. M. (Org.). Experiência e representação social: questões teóricas e metodológicas. São Paulo: Casa do Psicólogo, 2005. p. 93-130.

MOSCOVICI, S. A representação social da psicanálise. Rio de Janeiro: Zahar, 1978. (Original publicado em 1961)

OLIVEIRA, D. C.; GOMES, A. M. T.; MARQUES, S. C. Análise estatística de dados textuais na pesquisa das representações sociais: alguns princípios e uma aplicação ao campo da saúde. In: MENIN, M. S. S.; SHIMIZU, A. M. (Orgs.). Experiência e representação social: questões teóricas e metodológicas. São Paulo: Casa do Psicólogo, 2005. p. 157-200. 
PETRUCELLI, J. L.; FERREIRA, R.; BRANDÃO, A. Quatro anos de política de cotas: a opinião dos docentes. Programa de Políticas da Cor na Educação Brasileira. Laboratório de Políticas Públicas, Universidade do Estado do Rio de Janeiro, 2006. (Série Dados \& Debates 2)

RAMOS, L. H. Na margem negra do Rio: pesquisa numa escola do subúrbio carioca. Negro e a educação - Identidade Negra Pesquisas sobre o negro e a educação no Brasil. Anped e Ação Educativa, 2003. p.117-129.

SANTOS, N. R. Movimentos de educação popular: um estudo sobre os pré-vestibulares para negros e carentes no Estado do Rio de Janeiro. In: REUNIÃO DA ASSOCIAÇÃO NACIONAL DE PÓS-GRADUAÇÃO E PESQUISA EM EDUCAÇÃO - ANPEd, 27., 2004, Caxambu. Anais... Caxambu: ANPED, 2004. 1 CD-ROM

SANTOS, S. A. Ação afirmativa e mérito individual. In: SANTOS, R. E.; LOBATO, F. (Orgs.). Ações afirmativas. Políticas públicas contra as desigualdades raciais. Rio de Janeiro: DP\&A, 2003. p. 83-125.

SHIMIZU, A. M. et al. Black or poor? Social representations of affirmative action policies in Brazilian universities. In: INTERNATIONAL CONFERENCE ON SOCIAL REPRESENTATION: MEDIA \& SOCIETY. Roma, 2006. p. 127.

SILVÉRIO, V. R. 0 papel das ações afirmativas em contextos racializados: algumas anotações sobre o debate brasileiro. In: GONÇALVES E SILVA, P. B.; SILVÉRIO, V. R. Educação e ações afirmativas: entre a injustiça simbólica e a injustiça econômica. Brasília: Instituto Nacional de Estudos e Pesquisas Educacionais Anísio Teixeira, 2003. p. 55-80. Disponível em: <http:// www.inep.gov.br/download/catalogodinamico/titulosavulsos/2003/acoesafirmativas.pdf>. Acesso em: 05 jan. 2006.

SOUSA, C. P. Estudos de representação social e educação. Psicologia da Educação, São Paulo, n. 14/15, p.285-324, $1^{\circ}$ e $2^{\circ}$ semestre de 2002.

VELOSO, G. M. Cotas na universidade pública - direito ou privilégio In: REUNIÃO DA ASSOCIAÇÃO NACIONAL DE PÓS-GRADUAÇÃO E PESQUISA EM EDUCAÇÃO - ANPEd, 28., 2005, Caxambu. Anais... Caxambu: ANPEd, 2005. 1 CD-ROM.

VELOZ, M. C. T.; NASCIMENTO-SCHULZE, C. M.; CAMARGO, B. V. Representações sociais do envelhecimento. Psicologia Reflexão e Crítica, Porto Alegre, v. 12, n. 2, p. 479-502, 1999.

Recebido em 26.07.07

Aprovado em 16.06 .08

Maria Suzana De Stefano Menin é professora do Departamento de Educação e Programa de Pós-Graduação em Educação da UNESP/Presidente Prudente. E-mail: sumenin@uol.com.br

Alessandra de Morais Shimizu é professora do Departamento de Psicologia da Educação da UNESP/Marília. E-mail: ashimizu@flash.tv.br

Divino José da Silva é professor do Departamento de Educação e Programa de Pós-Graduação em Educação da UNESP/ Presidente Prudente. E-mail: divino.js21@uol.com.br

Fabio Lorenzi Cioldi é professor titular e diretor do Laboratório de Psicologia Social da Universidade de Genebra. Realiza pesquisas na área de Psicologia Social e em Representação Social. E-mail: Fabio.Lorenzi-Cioldi@pse.unige.ch

Fabricio Buschini é professor e pesquisador do Laboratório de Psicologia Social da Universidade de Genebra. Foi auxiliar de Pesquisa no Laboratório de Psicologia Social da École des Hautes Études en Sciences Sociales, Paris, trabalhando com Denise Jodelet e Serge Moscovici e realiza pesquisas na área de Psicologia Social e em Representação Social. 